\title{
THE INSIDE STORY OF HOW THE NYPD'S INTELLIGENCE DIVISION ADAPTED IN THE WAKE OF 9/11
}

\author{
David Cohen
}

In the aftermath of 9/11, the New York City Police Department (NYPD) made dramatic changes to respond to the new terrorist threat. The NYPD's ability to adapt to the evolving threat played a critical role in protecting New York City from subsequent terrorist attacks.

Through arrests and proactive intelligence-driven interventions, the NYPD and its partners foiled numerous plots. As NYPD deputy commissioner for intelligence from 2002 thru 2013, this is a firsthand account of how the NYPD re-engineered its intelligence structure, operations, and culture to address the post-9/11 threat to New York City.

\section{Re-engineering the Intelligence Division}

The NYPD Intelligence Division had a long and sometimes fabled history prior to $9 / 11$. Aside from a stable of extremely talented investigators and supervisors, it was not prepared for the intelligence mission of the post-9/11 environment. No organization was. Its re-engineering was unprecedented, unchartered, and profound. Members would be asked to take on responsibilities and roles that they did not expect to when they joined the NYPD.

Upon assuming office on January 1, 2002, New York City Mayor Michael Bloomberg appointed Raymond Kelly as police commissioner. Kelly immediately took action, tapping Frank Libutti, a retired Marine lieutenant general from the Pentagon's office of counterterrorism, to build and run the counterterrorism bureau and David Cohen, a 35-year veteran of the Central Intelligence Agency (CIA), to build and run the "new" Intelligence Division. Upon his appointment on January 25, 2002, Cohen immediately started the massive transformation of the division.

Three essential elements were required to achieve the desired transformation: leadership at the highest levels of the department, division, and line units; dramatic cultural change among investigators, analysts, and supervisors; and an environment that produced ideas, engagement, and integration.

\section{Leadership at the top}

An effective counterterrorism intelligence program at any level must receive its guidance from and have the ear of the organization's leader. For the NYPD Intelligence Division, this meant Kelly. His commitment to having a high-quality, effective, and responsible intelligence program was unambiguous, demanding, and unrelenting. These characteristics did not translate into micromanagement; rather, it required that his 


\section{David Cohen}

intelligence chief keep him informed, avoid surprises on matters on which he should be informed, and never withhold negative news or mistakes.

The mechanism that Kelly used to oversee the division's activities was a daily morning meeting with his deputy commissioner for intelligence and deputy commissioner for counterterrorism. He was briefed in substantial detail on what was known of the global and national terrorist picture, what the Division had learned about the threat locally, and the performance of individual programs. His strategy was broad gauged but also tightly focused. The strategy aimed to keep New York City as safe as possible within constitutional and legal bounds. At the tactical level, the goal was to decrease the odds of another terrorist attack against the city "a little bit, every day." "Thus, intelligence operations, investigations, and analysis demanded patience, persistence, and continuous improvement.

Regarding resources, Kelly never "taxed" the Intelligence Division, whether on personnel, technology, or funding, even when City Hall demanded "more with less." In terms of personnel, the city reduced the size of the NYPD by 7,000 uniformed personnel from 2002 to 2009 , a $17 \%$ reduction. ${ }^{2}$ Yet the Intelligence Division grew during this time. As the Division learned to absorb and effectively employ new technologies, it consistently received what Cohen requested. It led the department in building computer applications and communications technology, as well as information storage and retrieval systems.

\section{Changing the culture}

Law enforcement and counterterrorism intelligence operations are not necessarily a natural fit. NYPD detectives achieved success by making arrests. Many of these detectives found their way into the Intelligence Division prior to the $9 / 11$ attacks. Most came from the Narcotics Division, where success meant achieving a large number of arrests by quickly executed "buy-and-bust" operations. ${ }^{3}$ They were smart and energetic, but good intelligence operations demanded other qualities as well. Most importantly, patience in developing and testing assets and keeping them in place for long durations-sometimes years-and careful collection, documentation, and collation of intelligence information to be pieced together like a puzzle.

Blending these vastly different cultures required change at all levels. First and foremost, the detectives were weaned off making fast-moving arrests in large numbers. That meant an end to cigarette or drug cases that were traditionally used to build an inventory of confidential informants. New mechanisms were created to develop the confidential informants essential in addressing the rising threat of homegrown radicalization. In August 2004, for example, the NYPD arrested two homegrown jihadis-Shahawar Matin Siraj and James Elshafay-who plotted to blow up Manhattan's Herald Square subway station at East 34th Street and Sixth Avenue on the eve of the Republican National Convention to be held a block away. ${ }^{4}$

The transformation worked. Intelligence Division detectives soon blended their experience as investigators with the skills of the intelligence profession: different tradecraft, different use of informants, and the need for greater patience. Yet the pre-9/11 world of police intelligence required more change: how information was collected, combined, and shared. This meant automation.

In early 2002, the division still used a system in which debriefings were handwritten in triplicate using carbon paper; "forwarded" using an internal hand-carried mail delivery system; and kept in filing cabinets with limited chance of collation, integration, and analysis. Decades of operating this way had to change quickly. With the assistance of supervisors who recognized the need for change and persistence at all levels, automation was injected into the Division earlier than elsewhere in the NYPD.

The relationship between uniformed and civilian members of the Intelligence Division also impacted the effectiveness of its counterterrorism program. In almost any large organization, "silos" can easily emerge that impede effectiveness. At the CIA, for example, the challenge was linking operations officers with analysts. In the NYPD, the challenge was integrating uniformed personnel with civilian analysts. The Division hired its first of many civilian analysts in 2002 to help identify the "dots," connect those "dots," 
and then interpret what they meant and where they led. ${ }^{5}$ In short, bridging the cultural gap between the civilian and uniformed police was critical to the division's success.

The need for change never diminished. When the Division identified and fixed one issue, it often revealed a new set of issues requiring attention. Occasionally the layered constraints were a function of the 150-plus-year-old NYPD that served the department and the city well in addressing traditional crime. But if it impeded how intelligence addressed the terrorist threat, it was addressed. Identifying and fixing problems, or finding a better way to conduct intelligence, became an essential part of the division's DNAthe commitment to continuous improvement at every level and in every subordinate unit or program it undertook. For everyone in the Division, this was unrelenting and grueling and continued throughout its post-9/11 history.

\section{Ideas, engagement, and integration}

There was no roadmap, playbook, or consultants to tell the Intelligence Division how to reengineer itself to address the new terrorist threat. The NYPD had to figure it out on its own. The morning meeting between the police commissioner, the deputy commissioner of intelligence, and the deputy commissioner of counterterrorism helped drive the evolution. At the meeting, the leaders tossed around and decided on new ideas. Since almost all new initiatives involved a break or change from the past, communications among senior management, supervisors, and detectives were key to re-engineering the intelligence program.

The Division eventually established 16 separate units. Each had a unique responsibility, either in the intelligence collection, investigations, analysis, or support arena. Some overlapped on the edges, some dovetailed perfectly, and some were compartmentalized to protect the most sensitive sources and methods. The priority then became ensuring program managers—usually lieutenants—shared with colleagues their unit's activities, ensured that de-confliction was automatic, and enabled information to move seamlessly. To a person, they accomplished the task due to leadership from the captains, inspectors, and the most senior uniformed officer, Assistant Chief of the Intelligence Division Thomas Galati.

\section{Getting started: the NYPD hotline}

Prior to 9/11, all NYPD-produced terrorism-related intelligence was transferred for action to the Federal Bureau of Investigation's (FBI) New York Field Office Joint Terrorism Task Force (JTTF), where the NYPD had detailed a supervisor and a handful of detectives. The Intelligence Division had no role after passing the intelligence. After 9/11, its role expanded but only slightly; it ran down leads passed to them from the JTTF, as the JTTF lacked the capacity to personally investigate the growing number of leads.

By mid-February 2002, the Intelligence Division, as a matter of policy and practice, started to take a more assertive role in the growing number of terrorism-related cases. Three different sources now generated leads. First, the JTTF returned leads to the Division that it deemed unnecessary to pursue; the newly empowered Division would investigate if it determined there was reason. Second, the Division generated leads via its confidential informants. Third, the Division generated leads from its newly establish counterterrorism hotline.

Over a period of years, this hotline-located at the Division's 24-hour, seven-days-a-week operations desk-received thousands of calls from the public. The Division pursued each lead aggressively, and over the years, many calls resulted in full-scale investigations and arrests for matters related to terrorism. The rules were simple. When a call came in, the JTTF had first rights of refusal for follow-up; if they declined, the Division would act. The follow-up would be immediate, and the results would be documented in operational reports, filed, and a full investigative case initiated if warranted. 


\section{Expanding intelligence operations}

The Intelligence Division's ability to attract uniformed managers, supervisors, and detectives of the highest quality was a core strength of NYPD terrorism-related operations. With the strong support from Kelly, the Division brought on board some of the NYPD's best cadre. Every aspect of the Division benefited, none more so than the all-important undercover and confidential informant units.

\section{The deep undercover program}

The undercover program included the undercovers and their handlers and managers. The undercovers were young officers, in their early to mid-20s, almost all born abroad or first generation, and U.S. citizens with native fluency in languages ranging from Urdu to Bengali. The cadre grew to include men and women with roots in more than a dozen countries, mostly in South Asia, the Middle East, and North Africa. Instead of using experienced detectives who could not blend in with investigative subjects, these rookies entered the department through the Intelligence Division rather than the Police Academy. Hand selected, they were intelligent, highly motivated, and fully understood the complex challenges they would face.

As undercovers, they never entered an NYPD facility. They went through an intense six-month training program conducted by the undercover unit, usually in hotel rooms or locations far from New York City. The training class consisted of one student at a time, and instructors were often former undercovers who understood the professional and personnel issues that would arise living a full-time life under a different cover. The pressure on the undercovers, their handlers, and their managers was intense, as the stakes were high.

The undercovers blended naturally with the persons, clusters, and organizations that they were investigating. An undercover was instrumental in thwarting a case involving Mohamed Alessa and Carlos "Omar" Almonte, two New Jersey residents who were arrested as they attempted to depart New York to join the terrorist group al-Shabaab in Somalia. The pair had invited a remarkable 23-year-old undercover officer of Egyptian descent to join their cell after he spent months engaging with them. ${ }^{6}$ When the case became public, even the undercover officer's parents and girlfriend did not know that he had been living a separate life as an undercover for the previous four years.

While much of the deep undercover program cannot be discussed publicly due to case sensitivity and the safety of the undercovers involved, it can be said that they have been instrumental in dozens of cases. Their success is a direct result of the quality of the NYPD undercovers, their handlers, and their managers. One measure of the quality of the program is that when Samir Khan - the editor of al-Qaida in the Arabian Peninsula's Inspire magazine- - visited New York City before leaving for Yemen, NYPD undercovers were part of the welcoming party. ${ }^{7}$

\section{Confidential informants}

A confidential informant is "an individual requiring anonymity who provides useful information, directed assistance, or both, that enhance criminal investigations and furthers the mission of the agency, usually in exchange for financial or other consideration." ${ }^{8}$ They differ from citizens or witnesses who provide information in that the arrangement involves a relationship focusing on the trading of information for payment or prosecutorial considerations. ${ }^{9}$

Confidential informants served as the backbone of Intelligence Division operations, enabling the Division to get close to persons, clusters, or organizations under investigation. During these investigations, the Division understood and stayed firmly committed to avoiding any action that might be interpreted as entrapment. Division management at all levels knew this would be a first line of defense for defendants in a terrorist case. 
In one of many cases, the Division used two confidential informants and an undercover officer to investigate Jose Pimentel before arresting him in 2011 as he was constructing three bombs in his Washington Heights apartment. Pimentel, a self-radicalized internet disciple of al-Qaida in the Arabian Peninsula's Anwar al-Awlaqi, wanted to kill U.S. military personnel returning from Afghanistan. The case raised concerns of entrapment, ${ }^{10}$ and it was the lead argument in his defense. Nevertheless, he agreed to plead guilty to a single count on the indictment rather than go to trial and argue entrapment. ${ }^{11}$ Ultimately, the entrapment defense has almost always failed in post-9/11 terrorism cases, yet the Division remained committed to avoiding entrapping anyone. ${ }^{12}$

Having confidential informants who can gain access is essential; having detectives who can manage, control, and direct them is just as important. The intelligence units that worked with confidential informants were well trained. The Division often did well when it came to selecting confidential informants with access-sometimes too well. In one case, Najibullah Zazi and two other al-Qaida-trained associates from Queens, New York, planned multiple suicide attacks against the New York subway system in 2009. Asked by the FBI if it knew or could learn anything about Zazi, the Division appropriately approached one of its informants who happened to know Zazi's family well enough that he called Zazi's father, alerting him that law enforcement was asking about his son.

Zazi had terminated the plot the night before the alerting phone call. As Zazi stated at his trial, he realized he was under surveillance, especially when he faced an FBI-directed Port Authority vehicle stop at the George Washington Bridge following the 100-hour drive from Colorado to New York City. The case, with all its complications, demonstrates the depth of the NYPD informant cadre that it could call upon in time of need.

The Division developed and instituted an unparalleled vetting process for confidential informants used in the antiterrorism program. Operational testing was rigorous and continuous to ensure that informants were not merely reporting what they thought their investigator handlers wanted to hear or were trying to "dirty up" someone the informant wanted to harm. Their reporting streams were constantly reviewed for inconsistencies in what was already known about a target; a stringent mechanism was established that evaluated the ability of the investigators to manage their informants in the best way. Nothing was left to chance, as the review process itself consisted of the most experienced talent in the division. These reviews were critical and focused-it was not "checking the box."

\section{Adding civilian analysts to the division}

Commissioner Kelly wanted civilian analysts to be embedded in his divisions, so the NYPD recruited analysts with relevant backgrounds from the best schools. The Intelligence Division hired the first civilian analyst by early 2002. The Division was concerned about terrorist operatives entering the city from the port and needed expertise in this area, so they hired a Merchant Marine Academy graduate as their first analyst. In relatively short order, the civilian analyst program became a powerful force multiplier, and the analysts quickly became essential to the counterterrorism intelligence investigative program.

The blending of civilian analysts with investigators was neither automatic nor natural. The civilian cadre typically came from top graduate schools such as Harvard, Columbia, and Georgetown. While extremely intelligent, they often lacked intelligence experience; that came only with time on the job and an appreciation that ground-level analysis - what someone was saying to someone else in an apartment in Brooklyn, Queens, or Staten Island-was what mattered most. They learned quickly and played a powerful role in pursuing investigations and bringing perpetrators to prosecution.

Their intelligence, diligence, and creativity quickly won the respect of the investigative units with whom they worked. They were also helped by the management decision that, for operational security reasons, the operational reporting of each investigative unit was compartmented from one another. Within 
each unit, only the civilian analyst involved in the investigation was authorized to see all the reporting from the confidential informants and undercovers involved in the case.

Therefore, it fell to the analysts to collate the information, analyze it, identify gaps, and set requirements for both the undercover and confidential informant programs. Empowering the analysts helped make them full partners with the investigators, and the analyst and investigator always answered as a team. The integration of operations and analysis was now complete.

\section{The Cyber Unit}

Created in late 2002, the Cyber Unit's critical mission was to scour the internet to identify persons involved in planning or wanting to participate in terrorism-related actions. The Division was early to recognize the power of the internet in the context of terrorism; its concerns proved well founded.

First, al-Qaida and its affiliates increasingly communicated their ideology on the internet and via compact discs and videos, rapidly transforming the internet into a source of radicalization. Second, already radicalized individuals around the world used the internet to communicate with one another, forming "virtual" jihadi clusters, including with persons in the New York City area. Third, the internet had become a threatening source of information on bomb making, explosive devices of all kinds, and details on how to communicate securely.

The Intelligence Division, with the help of the Personnel Bureau, leveraged the Department's foreignlanguage capabilities to identify hundreds of NYPD members with foreign-language skills. It recruited some as cyber analysts to assess literature and conversations on jihadi websites and chat rooms, whether in Arabic, Farsi, Turkic, or Pashto. Their objective was to identify any mentions of New York City.

By scouring the internet, the Division began to identify organizations abroad that were known to be incubators of radicalization, or believed to be involved in terrorism, that might threaten New York. One example was al-Muhajiroon, an organization created by Omar Bakri Muhammad in the United Kingdom. Bakri, who was eventually expelled from the United Kingdom for extremist activity, sponsored a New York City chapter whose members included up to five people eventually arrested, convicted, and sentenced for various terrorism-related crimes. ${ }^{13}$ Other groups warranting attention included Lashkar-e-Tayyiba, Hezbollah, Hamas, and every other organization labeled as a terrorist group by the U.S. governmentwhether in South Asia, North Africa, the Middle East, or the Caucasus. ${ }^{14}$

The greatest impact resulted when cyber analysts-who included uniformed and civilian personnelcollaborated with civilian investigative analysts and investigative detectives. After the cyber team, always working in the unclassified world, identified a person of concern, the civilian analysts would conduct follow-up "forensic analysis," and, if needed, an investigation would begin involving the three (cyber, analyst, and detective) as a team.

As early as 2012, these teams started to assess how the Syrian rebellion attracted and produced radicalized persons in the New York area. In fact, even before the emergence of the Islamic State, the Division understood the risk and was preparing for its impact. It had a long record of looking for "lone wolves."

\section{The Demographics Unit}

One of the more controversial initiatives was the Demographics Unit, which was renamed the Zone Assessment Unit in 2010. Early in the Division's re-engineering process, it was clear that it lacked meaningful knowledge of either the demographic composition of the city or demographic concentrations. This was especially concerning during the post-9/11 period when there was alarm about al-Qaida cells or operatives establishing themselves in New York, New Jersey, and elsewhere in the United States. The importance of this knowledge is recognized in the Attorney General's Guidelines for Domestic FBI Operations that makes clear that such knowledge is an important FBI Field Office responsibility. ${ }^{15}$ 
With the risk of terrorism as the guidepost, the Division's concern included three points. First, if an adversarial operative, foreign or domestic, wanted to blend in so as not to be noticeable or appear suspicious, where are they likely to go? Where should intelligence or other policing efforts focus should the need arise?

Second, if an operative sought to recruit persons via their ability to associate or "hang out" with persons of similar background, where would the NYPD look if the Division received warnings from the federal government or elsewhere of such a risk?

Third, should events occur abroad — an attack on Hazaras in Pakistan, for example-where is the Hazara community in New York City concentrated, as they might need added police protection? Not knowing this in advance would be negligent in New York City.

From the NYPD's perspective, this knowledge was not frivolous, nor did it meet the definition of surveillance. Teams of plainclothes officers deployed to collect baseline knowledge about neighborhoods as opposed to individuals. The deployed teams were not involved in investigations or intelligence collection on persons or groups of persons. Nor did the NYPD send confidential informants or undercovers into mosques just to "listen." The rules were that a confidential informant or undercover could enter a mosque only if it were frequented by a person under investigation.

The American Civil Liberties Union still accused the NYPD of unlawful surveillance and unlawful profiling of Muslims. ${ }^{16}$ In the aftermath of Associated Press reports on the program, two major lawsuits were filed against the city: Hassan v. City of New York and Raza v. City of New York. As part of the settlements of both cases, which occurred several years after the unit had been disbanded in 2014, the NYPD was excused from any admission "that it has in any manner or way violated the rights of Plaintiffs or the rights of any other person or entity." Yet, the NYPD agreed to "establish a number of reforms designed to protect New York Muslims and others from discriminatory and unjustified surveillance" and a number of other requirements. ${ }^{17}$

\section{Creating an international program}

By the fall of 2002, the Intelligence Division deployed its first detective overseas. Eventually, the Division deployed personnel to 11 law enforcement organizations around the world, including, among others, London's Scotland Yard, Canada's Sûreté du Québec, and France's Paris Prefect. With few exceptions, these hand-picked assignees had native fluency in the language of the country assigned. The assignees to the Madrid Police, for example, spoke fluent Castilian Spanish, while those in the Middle East spoke Arabic. Their knowledge of terrorism and police intelligence made them welcome additions to the agencies that hosted them.

Their job was to represent the NYPD's interests, compare best counterterrorism practices, and ensure that questions that might show a nexus to New York City—a plot, group, or person, for example-were always asked by the host service when terrorism-related events or investigations occurred. Finally, they were expected to be on the site of any terrorist event as soon as possible to learn and report what and how the incident happened. It was vital that the NYPD learn from such events to improve its own counterterrorism initiatives.

It worked extremely well. For example, by having an accomplished lieutenant on site after the 2004 Madrid train bombings, the NYPD altered its critical response vehicle deployment strategy regarding subway stations. How it would handle terrorist crime scene material was also refined, having learned that the cell phone SIM card that ultimately led to the capture of the Madrid plotters was almost lost, as clean-up crews were about to discard the cell phone found at the scene.

Within 72 hours of the 2008 Mumbai attacks, the NYPD deployed a three-person team to India. In less than a week, the Division produced a 50-page report on what it learned from the incident and disseminated it to dozens of state and local U.S. law enforcement agencies, federal law enforcement agencies, and partners overseas. ${ }^{18}$ 
Commissioner Kelly also hosted a two-hour videoconference from Mumbai between the NYPD Mumbai team and 300 private-sector and law enforcement personnel. Based on what it learned, the NYPD quickly moved to train additional department personnel in the use of rifles, conducted internal hotel terrain mapping, established specialized hotel teams, and engaged in tabletop exercises using the Mumbai scenario.

Learning from the 2005 London bombings, Kelly initiated a random bag check program at some of New York's subway stations. This was the first of its kind in the United States, spearheaded by the NYPD Counterterrorism Bureau and its deputy commissioner, Michael A. Sheehan.

The information gathered from having officers on the scene during these various terrorist attacks abroad was vital, and sharing it with other police departments and agencies was standard operating procedure. Not surprisingly, it was not long before the Division had become a valuable source of information and insight for many of the foreign security services with which it worked.

The Division hosted hundreds of visits by foreign security services, provided training to some, and won their respect for the Division's professionalism and effectiveness. These meetings revealed the uniqueness of the NYPD. Few, if any, foreign security or intelligence services had their civilian intelligence analysts and investigators so thoroughly integrated. Few, if any, had an embedded undercover program staffed with full-time employees of their organization; more typically, they used only confidential informants or non-staff undercovers.

Many seemed to be constrained by unit-specific parochial perspectives that clearly interfered with the organization-wide integration of programs, people, and information. While they admired the NYPD's intelligence program, structural or cultural obstacles often prevented them from being able to replicate important elements of it.

\section{Sharing information and expanding partnerships}

Aside from leadership, information sharing was the single most important factor driving the Division's effectiveness in the years following 9/11. In its narrowest form, this meant sharing information between individual analysts and detectives, between teams of analysts and detectives, between the Division's 16 counterterrorism units, and ultimately between one organization and another. While easier said than done, information sharing was effective due to its leadership, culture, and technology.

Its leaders-Kelly, Cohen, and Sheehan - conducted daily meetings together and required their subordinates to be synchronized as well. Culturally, the department recognized that terrorism spanned not only jurisdictions but state and international borders, so it was important to expand its network to protect not only protect New York City but others around the world. Finally, technology was critical to digitizing reports and information that could be easily shared or searched.

Creating an environment of information sharing was made easier because its work was not U.S. government classified. The Division established its own classification standards based on the source of the reporting: undercovers, confidential informants, or cyber collection, for example. All intelligence reports/ memoranda produced by the Division carried an NYPD SECRET classification stamp.

\section{Operation Sentry: Expanding regional partnerships}

The NYPD is a vast organization by any measure. In 2002, when the process of restructuring it to address the terrorist threat began, there were 42,000 uniformed members and 15,000 civilians. Many organizations that large and powerful develop a view that they can accomplish what they need without outside assistance. But the Division rejected that perspective. It recognized that it needed partners to protect New York City from another attack.

This regional approach was the foundation of Operation Sentry, which was designed to build partnerships across the country. While New York City remained a primary target, the plotting, planning, training, 
and deployment often emanated from outside the city. In response, the Division started Operation Sentry by establishing special relationships with local law enforcement agencies surrounding the city.

Several features made Operation Sentry effective and attractive to each member. First, the Division explicitly called for assistance. Second, the Division committed some of its best detectives and analysts to the operation.

Third, the NYPD provided training, advice, and support to alliance members. This extended beyond counterterrorism matters and into traditional police issues. In this regard, the Division became the entry point for partners into the vast resources and expertise of the NYPD. When the Hoboken, New Jersey, police department needed scuba divers to assist in retrieving a body from the Hudson River, the first call for help came to the Division. ${ }^{19}$

Fourth, information sharing was complete, transparent, and based on a policy of "push" rather than "pull." Division policy and practice were to disseminate information quickly, in a useable form, to whomever needed it without waiting for a partner to request it. Fifth, Division leaders responsible for managing Operation Sentry were committed to a "no surprises" policy; any activity the Division undertook in a member's territory was always completed with the knowledge and, when needed, help of the partner in place. The policy was unambiguous and strongly supported by every Operation Sentry officer and partner.

The results of this collaboration were remarkable. Multiple terrorism-related investigations, arrests, and convictions resulted from joint efforts with the Suffolk and Nassau County police departments, and dozens of cyber leads produced by the Division's Cyber Unit were shared with local police departments around the country as well as the federal government.

A prime example of this successful collaboration is one of the few "illegal cigarette" cases given the greenlight by Cohen. Driving this decision was the fact that one of the targets in the case involved a financial associate of Omar Abdel Rahman (also known as the "blind sheikh") and an individual linked to Hamas' senior U.S. fundraiser. Another individual swept up in the "cigarette case" was the suspected sanctioner of Rashid Baz (who killed Jewish student Ari Halberstam on the Brooklyn Bridge in 1994). ${ }^{20}$ The case itself emerged from confidential informant leads obtained in conjunction with upstate New York police departments.

\section{Operation Nexus: expanding private sector partnerships}

Almost from the start, the Intelligence Division initiated a program to reach out to the private sector to engage it in "watching out" for any anomalous purchase that should raise concern about possible terrorist activity. A number of steps were taken to this end.

First, the Division identified material that could be used in a terrorist plot based on events overseas and a careful scrub of information available on the internet. Second, the Division identified all businesses in the tri-state area that bought, sold, inventoried, or transported such material. Third, it deployed teams of detectives to visit each of these locations, meet with managers or staff who were informed about how products in their possession had been used in terrorist attacks abroad, asked to remain vigilant for any purchases that were inconsistent with normal practices of their business, and advised to report that activity to the FBI and the NYPD counterterrorism hotline.

During what became known as Operation Nexus, detectives conducted more than 25,000 visits to area businesses. ${ }^{21}$ To raise awareness, they also spoke to industry conventions such as the aircraft spraying convention, the unmanned aerial vehicle convention, and firearms shows. Detectives also made special links with relevant firms. Intelligence detectives, for example, established a connection with the fuel trucking industry in the New York-New Jersey region to ensure that any missing fuel trucks would be immediately reported to Division's Operations Unit for response.

After the Boston Marathon bombings in 2013, Operation Nexus established a link with the country's largest fireworks company, headquartered in Pennsylvania. A company store, unknowingly, was the source of fireworks bought by Faisal Shahzad as part of his plan to detonate a bomb in Times Square in 2010.22 
The Tsarnaev brothers purchased fireworks from one of the company's New Hampshire stores to gain access to the black powder contained in the fireworks as part of the Boston Marathon bombings. ${ }^{23}$ According to the fireworks company, Operation Nexus outreach was the first time it had been contacted by any law enforcement agency. Unfortunately, this came only after the Boston Marathon bombings, when the Division connected the two purchases.

\section{Expanding federal government partnerships}

The NYPD leadership decision to carve out a role in defending New York City against another terrorist attack was not immediately understood or necessarily welcomed by all U.S. government agencies responsible for counterterrorism. Many believed NYPD intelligence should have a narrower, more traditional role that excluded terrorism issues. But the NYPD leadership believed that to defend the city, it could not rely solely on the federal government to find the dots, connect them, and pursue where or to whom they would lead. That system had failed in 1993 and 2001. Therefore, knowing its terrain better than the federal government, the mayor and commissioner directed the NYPD to take a much more active role than had been the case historically.

The greatest resistance came from the FBI, claiming the Intelligence Division was overeager and amateur. While there was much acrimony, that tension at no time interfered with either FBI or NYPD counterterrorism endeavors. Over time, these tensions diminished as old enmities faded. Today, the NYPD-FBI relationship remains strong.

The NYPD civilian analyst cadre were extremely important in this steadily improving relationship, as they carried the bulk of the information-sharing load with the FBI and other federal agencies. This took the form of briefings as well as extensive written documentation. Analysts conducted hundreds of briefings to FBI personnel and produced more than 1,000 special reports, referred to as "Sitreps," that were provided to the FBI. The Division also developed close partnerships with U.S. prosecutors as far afield as the Eastern District of Virginia that successfully prosecuted Division cases that others would not.

Throughout the 2002-2013 period, the Division posted highly qualified personnel to various U.S. government agencies in the New York City area and in Washington. These agencies welcomed the information and quality of personnel offered by the Division. Of greatest value to these agencies was the "view from the ground" provided by the NYPD analysts.

One point of media criticism focused on the NYPD-CIA relationship. ${ }^{24}$ The media focused on a portion of the CIA inspector general report that noted "a number of irregular personnel practices . . . [some] lack of formal documentation in some important instances, and varying degrees of management and legal oversight." ${ }^{25}$ Despite some unintentional administrative missteps, the six month review concluded that the CIA-NYPD relationship did not violate the 1947 National Security Act or Executive Order 12333, ${ }^{26}$ the relationship had been approved at the highest levels of both organizations, and no improprieties by either CIA or NYPD personnel had occurred. ${ }^{27}$

Despite these findings, the CIA ultimately terminated the relationship in 2012, perhaps due to the urging of the director of national intelligence, who stated in a public hearing that it is "not a good optic to have CIA involved in any city-level police department." ${ }^{28}$ Many in the NYPD believed that optics should not have been a deciding factor in the decision, considering that New York City remained a top terrorist target.

\section{Legal oversight of intelligence}

Given the sensitivity of the Intelligence Division's activities, legal oversight was crucial and welcomed. The U.S. Constitution and federal court guidelines - the Handschu guidelines ${ }^{29}$ - provided the boundaries that department and Division leadership was committed and obligated to work within. That said, it required 
a legal staff to determine whether an activity crossed those boundaries, came close to them and therefore needed to be avoided or altered, or was within the boundaries. The NYPD leadership treated these matters with the utmost conviction and did so openly for all staff members to see.

The Division was fortunate to have a vigorous and tough-minded civilian legal counsel, Assistant Commissioner Stuart Parker, who answered to Commissioner Kelly through the General Counsel rather than the Intelligence Division chain of command. Under such a structure, legal counsel could not be ignored. Legal oversight, however, required knowledge of the Division's actual activities. Thus, there was a need for complete transparency.

To ensure transparency, the deputy commissioner for intelligence implemented several mechanisms. First, the assistant commissioner for legal matters attended the Division's morning meetings, as that was where policy and operational guidance were surfaced, discussed, and decided upon. Second, the assistant commissioner for legal matters or his staff were authorized to attend any meeting held by any Division, team, unit, branch, or any combination of them, and the legal staff was to be informed of such meetings in advance. Third, the assistant commissioner or his staff reviewed operational reports prepared by Division detectives and analysts to ensure that activity on the ground comported with legal guidelines.

In short, the Division established mechanisms that ensured complete transparency and the legal oversight required by the court and the police commissioner.

\section{Conclusion}

While the re-engineered Intelligence Division had its critics, the results are tough to refute. Of the 16 known terrorist plots directed against the city by al-Qaida, its affiliates, or al-Qaida-inspired homegrown terrorists during 2002-2013, not a single one succeeded. The Division was responsible for stopping three of the plots and played a significant role in foiling three others. As discussed in the chapter, an undercover officer was central to the Alessa and Almonte cases, as well as in the arrests of individuals attempting to join al-Shabaab and al-Qaida in the Arabian Peninsula.

The Shehadah case is exemplary of what was accomplished. In 2008, Abdel Hameed Shehadah bought a one-way ticket to Pakistan to attend a terrorist training camp but was turned back by Pakistani officials based on intelligence provided by an NYPD undercover officer. He was subsequently arrested upon his return. ${ }^{30}$ Likewise, an NYPD undercover and confidential informant contributed to the arrest of Justin Kaliebe and Marcos "Ali" Zea, who were attempting to join al-Qaida in the Arabian Peninsula. ${ }^{31}$

There are many lessons to be drawn from the experience of the NYPD Intelligence Division during this post-9/11 era. The most central lesson is the overarching role of leadership in launching an endeavor never before taken on, in terms of scope and depth, by a local law enforcement agency. Commissioner Kelly's role was essential, critical, and overarching. None of this could have happened without his vision and strength of purpose. He seeded and then allowed the Division to thrive. Thus, strong, articulate leadership with unambiguous integrity at the top stands out as the single most important lesson.

The second lesson is the role of culture. Terrorism spans jurisdictions and nations, so counterterrorism must likewise span jurisdictions and nations. Civilian analysts were hired to partner with seasoned detectives. Partnerships were expanded through Operation Shield and Operation Nexus, and NYPD officers were even sent to overseas departments. Thwarting the many attempted attacks on New York City often involved multiple departments and agencies.

As the person who headed the NYPD Intelligence Division during this period, the third crucial lesson involves people. The Division came to be populated with smart, hard-working, highly motivated senior officers who were willing to learn and lead. Nobody filled this role or served as a better role model for others than Chief Thomas Galati, who had this author's complete confidence, shared in all decision-making, and had the trust of all concerned. 


\section{David Cohen}

The underlying lessons woven through this chapter have application for the challenges faced by Western European intelligence and security services in Mumbai, Tokyo, Bangkok, and other major urban centers. In brief, the Intelligence Division's key strengths involved more integrated intelligence and security programs; aggressive use of civilian analysts teamed with investigators; and support from a cadre of undercover officers who, while living a covert life, are fully embedded into the agencies for which they work. Yet it is important to operate within the rule of law. These are the minimum requirements for enhanced security and safety.

\section{Notes}

1 This quote is based on the author's recollections.

2 Al Baker, "Crime Drops Despite Fewer Officers in Lean Times," New York Times, July 17, 2009, www.nytimes. com/2009/07/18/nyregion/18nypd.html.

3 For more on buy-and-bust operations, see Michelle Mark, "Undercover New York Police Officers are Reportedly Targeting Addicts Instead of Drug Dealers," Business Insider, April 4, 2016, www.businessinsider.com/ undercover-new-york-police-officers-using-buy-and-bust-tactics-2016-4.

4 William K. Rashbaum, "Man Gets 30 Years in Subway Bomb Plot," New York Times, January 9, 2007, www. nytimes.com/2007/01/09/nyregion/09plot.html.

5 David Cohen, "NYPD's Intelligence Division: Answering the Terrorism Challenge Post 9/11," The Cipher Brief(blog), September 15, 2016, www.thecipherbrief.com/column_article/nypds-intelligence-division-answeringthe-terrorism-challenge-post-911-2.

6 U.S.A. v. Mohamed Alessa and Carlos E. Almonte, Criminal Complaint (District of New Jersey, 2010).

7 Jesse Morton and Mitchell Silber, "NYPD vs. Revolution Muslim," CTC Sentinel 11, no. 4 (2018): 1-7.

8 "Confidential Informants: Concepts and Issues Paper," IACP Law Enforcement Policy Center, August 2017, www. theiacp.org/sites/default/files/all/c/ConfidentialInformantsPaper2017.pdf.

9 Ibid.

10 William K. Rashbaum and Joseph Goldstein, "In Jose Pimentel Terror Case, FBI Worries Over Informer," New York Times, November 21, 2011, www.nytimes.com/2011/11/22/nyregion/for-jose-pimentel-bomb-plot-suspect-an-online-trail.html.

11 James C. McKinley Jr., "Judge Imposes 16-Year Term for Manhattan Man in Pipe Bomb Case," New York Times, March 25, 2014, www.nytimes.com/2014/03/26/nyregion/judge-imposes-16-year-term-for-manhattan-man-inpipe-bomb-case.html.

12 Jesse J. Norris, "Accounting for the (Almost Complete) Failure of the Entrapment Defense in Post-9/11 US Terrorism Cases," Law \& Social Inquiry 45, no. 1 (2020): 194-225.

13 Richard Esposito, "Feds Request Leniency for Terrorist Who Still Backs Killing of Americans," ABC News, March 7, 2011, https://abcnews.go.com/Blotter/mohammed-babar-convicted-aiding-al-qaeda-early-release/ story?id $=13078465$.

14 For a current list, see "Foreign Terrorist Organizations," U.S. Department of State, www.state.gov/foreignterrorist-organizations/.

15 Michael Mukasey, "Attorney General's Guidelines for Domestic FBI Operations," U.S. Department of Justice, September 29, 2008, www.justice.gov/archive/opa/docs/guidelines.pdf.

16 "The NYPD's Discriminatory Surveillance of Muslim Communities," ACLU, no date, www.aclu.org/other/ factsheet-nypd-muslim-surveillance-program.

17 Bridge Initiative Team, "Factsheet: The NYPD Muslim Surveillance and Mapping Program," Georgetown University, May 11, 2020, https://bridge.georgetown.edu/research/factsheet-the-nypd-muslim-surveillance-andmapping-program/.

18 Intelligence Division, Mumbai Attack Analysis (New York: New York City Police Department, 2008), https://info. publicintelligence.net/nypdmumbaireport.pdf.

19 A.G. Sulzberger and Al Baker, "Police Divers Recover Bodies and Plane Wreckage," New York Times, August 11, 2009, https://cityroom.blogs.nytimes.com/2009/08/11/police-divers-renew-effort-to-salvage-plane/?src=twt\&twt= CityRoom.

20 Mark Hosenball, “New York Says Breaks Cigarette-Smuggling Ring Linked to Militants," Reuters, May 16, 2013, https://fr.reuters.com/article/us-crime-cigarettes-mideast-idUSBRE94F1C320130516.

21 NYPD Shield, “Operation Nexus," New York City Police Department, November 10, 2020, www.nypdshield.org/ public/nexus.aspx. 
22 Cara Buckley, "Pennsylvania Fireworks Store Owner Recalls Shahzad," New York Times, May 6, 2010 , www. nytimes.com/2010/05/06/nyregion/06fireworks.html.

23 Lauren Dezenski, “Older Marathon Bombing Suspect Purchased Fireworks at N.H. Store,” Boston Globe, April 23, 2013, www.boston.com/uncategorized/noprimarytagmatch/2013/04/23/older-marathon-bombing-suspect-pur chased-fireworks-at-n-h-store-official-says.

24 See, for example, Charlie Savage, "CIA Report Finds Concerns With Ties to New York Police," New York Times, June 26, 2013, www.nytimes.com/2013/06/27/nyregion/cia-sees-concerns-on-ties-to-new-york-police.html.

25 CIA, "Review of the CIA-NYPD Relationship" (official memorandum, Langley, VA: CIA, December 27, 2011).

26 "Executive Order 12333 of December 4, 1981 United States Intelligence Activities," Code of Federal Regulations, title 3 (1981): 200.

27 CIA, "Review of the CIA-NYPD Relationship."

28 Mark Mazzetti, “CIA Examining Legality of Work With Police Dept.," New York Times, September 13, 2011, www.nytimes.com/2011/09/14/nyregion/cia-examining-legality-of-its-work-with-new-york-police.html.

29 The Handschu guidelines govern how the NYPD investigates political activity. These guidelines were a product of surveillance of political groups, like the Black Panthers, in the 1960s and 70s.

30 Tom Hays, "NYC Man Gets 13 Years in Terror Training Case," Associated Press, September 20, 2013, https:// apnews.com/article/eefbdb26a6b44f2f9a5c9b08556a25b4.

31 U.S. Attorney's Office, "Long Island Man Pleads Guilty to Attempting to Join Al-Qaeda in the Arabian Peninsula and Obstruction of Justice," U.S. Department of Justice, September 9, 2014, www.justice.gov/usao-edny/pr/ long-island-man-pleads-guilty-attempting-join-al-qaeda-arabian-peninsula-and. 